Key words: testing space manipulators, free floating space robots, air bearing table, microgravity operations, epicycloid gear

\author{
KAROL SEWERYN*, KAMIL GRASSMANN*, KONRAD RUTKOWSKI*, \\ TOMASZ RYBUS* ${ }^{*}$ ROMAN WAWRZASZEK*
}

\title{
DESIGN AND DEVELOPMENT OF TWO MANIPULATORS AS A KEY ELEMENT OF A SPACE ROBOT TESTING FACILITY
}

\begin{abstract}
The process of designing control systems for devices operating in microgravity, on-orbit environment, requires testing to verify the effectiveness and characteristics of the algorithms. The key issue is to design a relevant environment in terrestrial conditions that affects both the linear and angular three-dimensional motion of a rigid body. This paper contains a description of the mechanical aspects of two test beds used to evaluate control algorithms planned for use in a space manipulator. Two solutions are presented: (i) a planar manipulator with a free base placed on an air-bearing table; and (ii) a test bed with a 7-DOF manipulator fixed through a force-torque measurement system to the base.
\end{abstract}

\section{Introduction}

Significant interest in satellite systems capable of servicing other satellites has developed in recent years [1]. Typically, in such manoeuvres, a malfunctioning satellite in orbit is repaired by a service satellite. Three major actions occur during this manoeuvre: (i) target observation and problem identification; (ii) docking and composite object rigidisation and stabilisation; and (iii) servicing, replacing and deorbiting actions [2, 3]. Economic analyses [4] show that communication satellites placed in GEO orbit have significant potential for servicing systems. In the past, three space missions were performed to verify and test the key technologies of an automatic orbital servicing system. The first, called ETS-VII, which was organised by the National Space Development Agency in Japan in 1997, was executed to conduct several stages of a servicing mission between two satellites, one of which had a manipulator arm [5].

* Space Research Centre of the Polish Academy of Sciences (CBK PAN), ul. Bartycka 18a, 00-716Warsaw,Poland; e-mail:kseweryn@cbk.waw.pl 
Another mission, organised by NASA in 2005, was performed to test a vision system that provided input to the AOCS to enable close manoeuvres around another satellite [6]. Its last mission, called the "Orbital Express", which was organised by DARPA in 2007, verified the possibility of autonomous refuelling, checked the service satellite ASTRO robotic arm's capabilities and tested a satellite reconfiguration process [7].

Satellites equipped with manipulators can also provide a solution to the problem of collecting space debris [8], which is currently a significant hazard for satellite systems. For upcoming space missions (manned or unmanned) aimed at space exploration or mineral mining from the asteroid, these types of systems may be invaluable; they could be used for the autonomous construction of large space components (e.g., transfer stations, spacecraft) and also help repair space components or gather soil samples for further analysis.

One of the key stages of a satellite service mission is the capture manoeuvre, deceleration and docking of a damaged satellite. The importance of this type of manoeuvre stems from the need for automation of the processes implemented in orbit, a process that has been controlled manually to date. In the case of a manipulator-equipped satellite, the motion is characterize by dynamic coupling between manipulator and satellite and as a consequence every move of the manipulator produces satellite movement. This effects significantly complicate the robotic arm and satellite control systems either in guidance, navigation and control parts. The review of the current state of the art related to space robotic technologies can be found in [9]. The manipulators technologies are shown in a few papers e.g. (i) the European Robotic Arm (ERA) for International Space Station (ISS) [10], (ii) Canadian large robot arms (SSRMS and SPDM) on the ISS [11] and (iii) DLR lightweight robot arms (now at the 3rd generation) [12].

Testing space robots is a challenge in terrestrial conditions, primarily because it is difficult to reduce the effects of gravity on mechanical systems. In orbital conditions, gravity is near zero; however, testing have to be conducted in terrestrial environment due to economical aspects. Several testing facilities have been developed where all tests are performed on a flat surface perpendicular to the force of gravity $[13,14,15]$. In these facilities, a mobile base moving on an air bearing system reduces friction to near zero. These test beds allow for the examination of satellite behaviour induced by manipulator movements and testing of the entire manipulator-equipped satellite's position and orientation control systems during a satellite capture manoeuvre. However, due the nature of Euler equation describing the rigid body rotational motion, the nonlinearities in space robots are stronger in spatial systems than in flat systems. For example, the friction in joints in spatial manipulator arm can 
create the torque in axes perpendicular to joint axis of ration. Such behaviour cannot be observe in flat system, and therefore it is necessary to determine the influences of these nonlinearities on mechanical components and the control system before working in flight conditions. In Europe, available are some testing systems where commercial robotic arms are used to simulate chaser and target behaviour induced by space manipulator arms. One of them is EPOS facility in Germany [16] and another Platform-Art in Spain [17]. The disadvantage of these systems is the non-trivial solution assuring the momentum conservation of the testing object.

In the frame of the project "Design and construction of a prototype of the manipulator as a key component of the satellite orbit servicing system", which was implemented under the LIDER programme of the National Centre for Research and Development, the manipulator arm WMS1 LEMUR was developed [18]. One of the key novelty in that project was testing approach where two test beds were used to test control algorithms and gain experience in designing these types of systems and their associated components. Specifically, the testing setups were used to validate numerical models of manipulator arms mounted on satellite during on orbit proximity operations. A correlated model is essential for designing satellite control systems, because it reduces the costs of system implementation and shortens the prototyping time. The first test bed is a planar system equipped with a free base and a manipulator with 2 DOF. An air bearing system was placed either under the moving base and through a suspension system under the manipulator links. Such a solution allows for the mounting of heavy joints and long links. The second test system contained a 7-DOF manipulator with a constant-tension gravity compensation system. An additional advantage of the second test bed is the ability to measure the influence of the manipulator in the form of forces and torques on the base. With this information, it is possible to validate how satellite motion is affected by manipulator movement.

The mentioned test facilities are described in the following sections of this paper. First, the flat air bearing test bed system with a free base and a twolink planar manipulator installed on a granite table is described, followed by an analysis of the system consisting of a 7-DOF manipulator equipped with a suspension system. The paper is concluded in the last section.

\section{2-DoF free floating manipulator on air bearing table}

A planar system is designed to simulate the dynamics of a free-floating satellite (i.e., no position control) with a two-link manipulator operating in a reduced gravity environment. The mechanical configuration of the test bed is presented in Fig. 1. The test bed consists of a 2-DOF manipulator with a free- 
floating base suspended on air bearings, a granite table and a vision system for determining the position and configuration of the manipulator. The granite table, on which the satellite-manipulator system moves, has dimensions of $2 \times 3 \mathrm{~m}$ and is larger than many similar solutions [19]. The detailed design of the manipulator is shown in Fig. 2, while its main mechanical parameters are presented in Table 1.

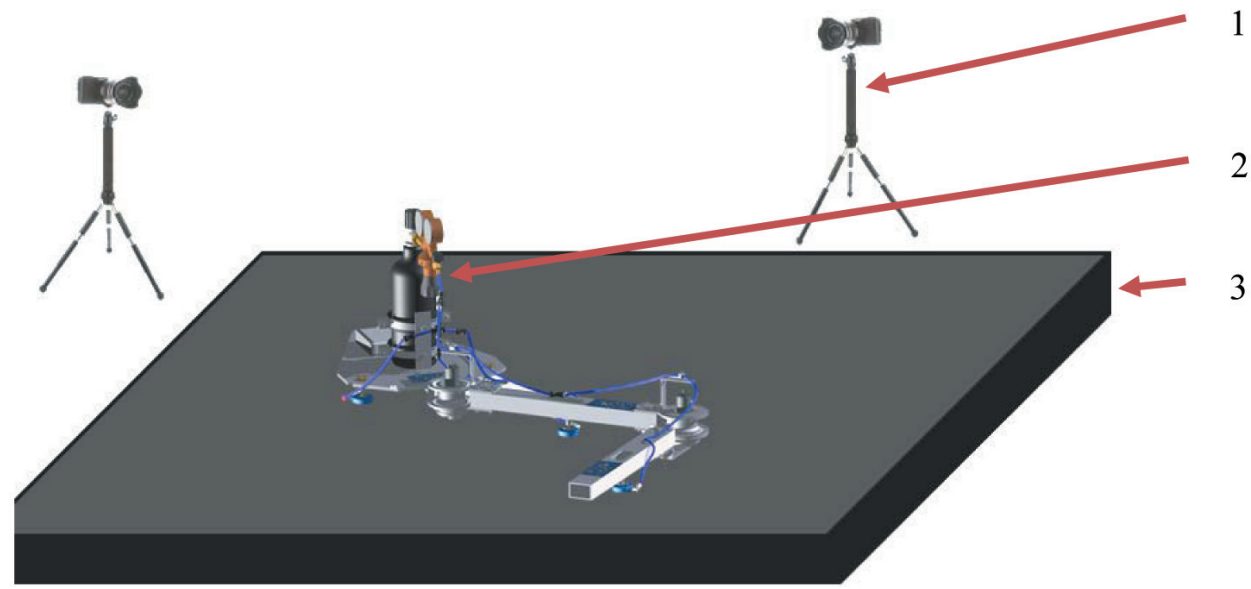

Fig. 1. Test bed no. I. 1 - vision system, 2 - free - floating platform with 2 links manipulator, 3 - granite table

To operate properly, the free-base manipulator was required to work in the horizontal plane as a planar system with a maximum reduction of friction against the reference surface. Well finished granite table $(\mathrm{Ra}=1.2)$ together with air bearings system based on porous materials technology was used to achieve the friction of order $10^{-5}[/]$.

Table 1.

Geometric and mass properties of the planar satellite-manipulator system

\begin{tabular}{|c|l|c|}
\hline & \multicolumn{1}{|c|}{ Parameter } & Value \\
\hline 1 & Total mass & $18.9 \mathrm{~kg}$ \\
\hline 2 & Manipulator range & $1.22 \mathrm{~m}$ \\
\hline 3 & Ratio of manipulator mass to platform mass & 0.465 \\
\hline 4 & Maximum rate in joints & $14 \mathrm{rpm}$ \\
\hline 5 & Maximum torque in joints & $4 \mathrm{Nm}$ \\
\hline
\end{tabular}

The primary design driver was to guarantee the compensation of gravitational effects. It was not trivial since the entire mechanism moves on the granite table on five air bearings: one air bearing supports each manipulator link and three are attached to the free base. Therefore, the system is over-constrained 
since the plane is perfectly defined by three not five points. This cause the need to develop a method of fixing the air bearings so that they worked in a perfect plane parallel to the table surface. After trade off, the best solution was to connect manipulator joints to air bearings through specially designed anisotropic spring element with stiffness constants equal to $1.6 \mathrm{~N} / \mathrm{mm}$ in planes' directions and $0.15 \mathrm{~N} / \mathrm{mm}$ out of plane. As an effect, the system is flexible only in the direction of gravity vector while resisting other forces. Stiffness in rotational direction was achieved by doubling the springs. The joint cross section is provided in Fig. 3.

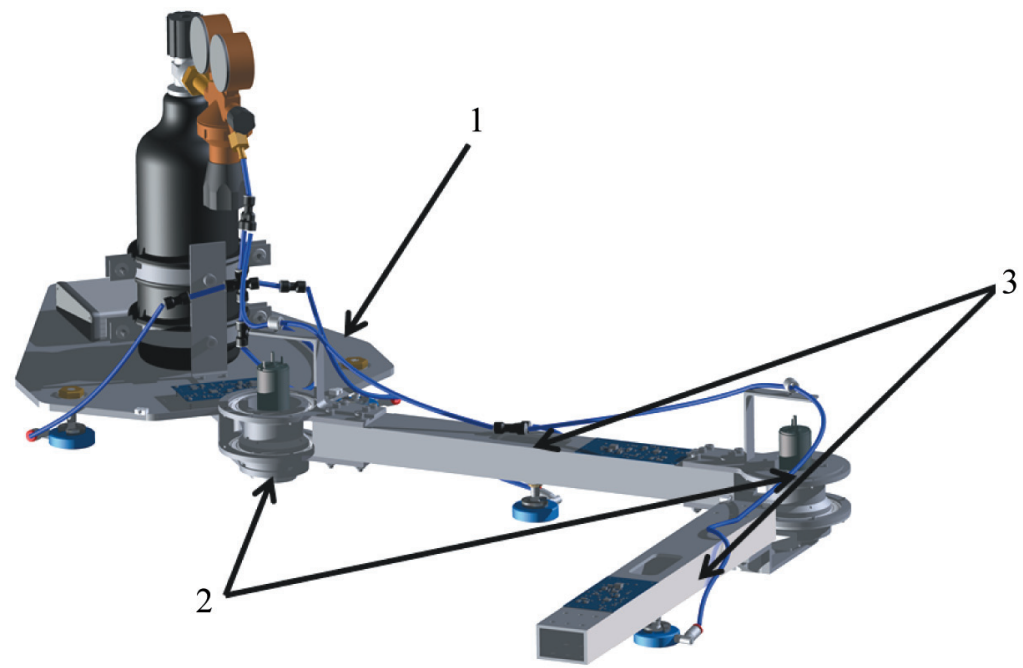

Fig. 2. Free-base manipulator. 1 - manipulator base, 2 - kinematic joints, 3 - manipulator links

The second design driver was connected with inertia of both: manipulator arm and platform. In the nominal configuration, the ratio of manipulator mass to platform mass is close to 0.5 and it is the most difficult configuration in terms of dynamical cross couplings between those two elements. If specific ratio is needed, there is a possibility to adjust both mass and inertia of manipulator or base.

During design process, some additional technical constraints were solved. As it was indicated above, the free base manipulator does not have any physical connection between the manipulator and inertial frame; any interaction between the manipulator and ground station could cause a non-realistic behaviour of the system. For this reason, the manipulator control unit was placed on the base and was wirelessly controlled by a PC. The air bearings were also powered by air from a canister attached to the manipulator base.

The manipulator joint had to provide an accurate backlash-free connection between its links. Therefore, the joint is equipped with DC motor, har- 
monic drives and absolute 24bits optical encoder. It is important that small flexibility induced to the system by resistant plates is, by design, not to affect the accurate measurements performed by optical encoder. A cross section of the manipulator joint is shown in Fig. 3.

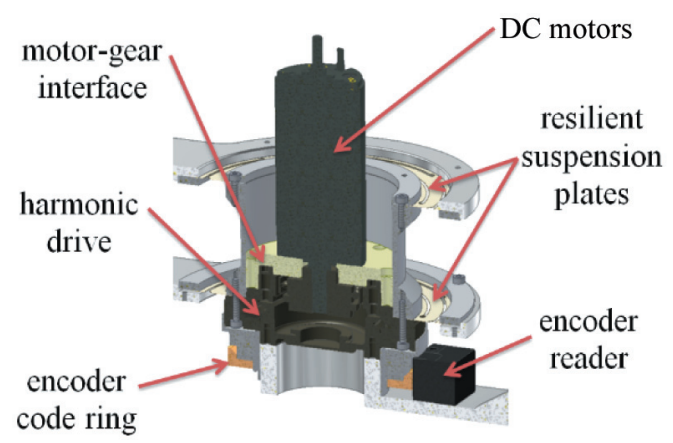

Fig. 3. Cross section of the manipulator joint

All the mentioned aspects were transferred for the detailed design of manipulator arm and a free floating platform. After manufacturing of elements in CBK workshop, and assembling and integration in LMRS CBK laboratory, it was functionally tested on the granite table (Fig. 4).

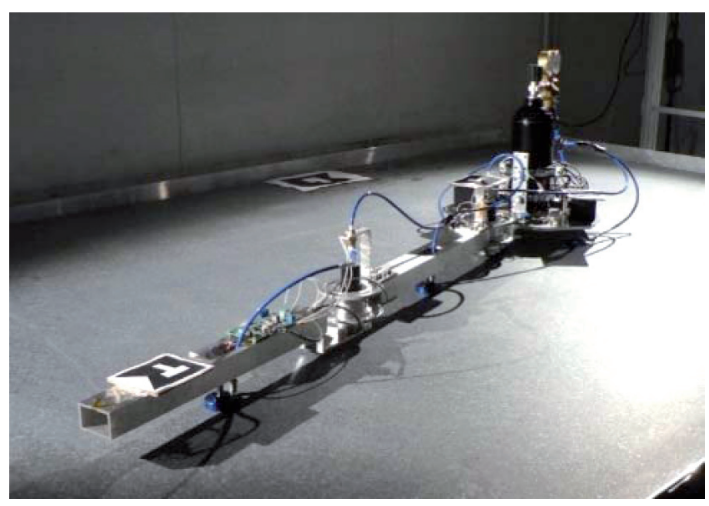

Fig. 4. 2-DOF manipulator prototype - test bed I

To compare the real system behaviour to the numerical simulations, the test bed on the granite table was equipped with a vision system to measure the absolute position of the base and the particular links of the manipulator. During the tests, execution the end-effector was moving on a straight-line trajectory in inertial space. The GJM-based algorithm [20] was used to compute offline positions of the joints, which was realized by a simple PID controller. In the performed tests, no feedback from the end-effector position was applied. The obtained results $[21,22]$ were compared with the simulation data and the 
obtained error is provided in Fig. 5. Two types of error are presented: (i) the first one is purely geometrical and shows the minimum distance between the measured point and simulated one, (ii) the second one shows the distance between the measured and simulated point of trajectory in specified time. Due to nonholonomic nature of that system, the second way of error calculation is more valuable.

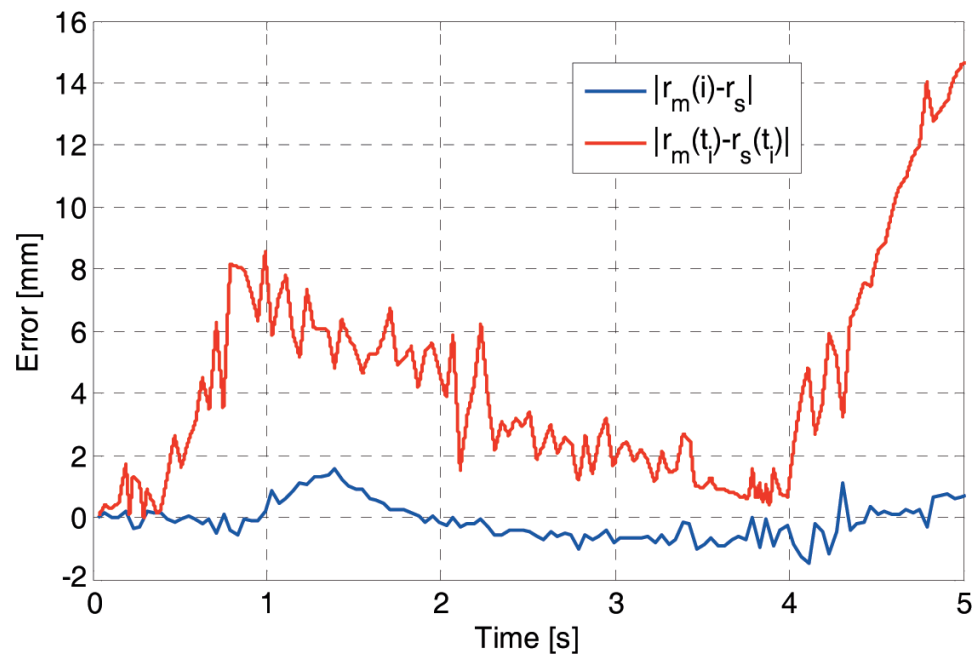

Fig. 5. The errors between the measured and simulated end-effector trajectory

The standard deviation of errors is, respectively, $0.6 \mathrm{~mm}$ and $3.4 \mathrm{~mm}$. The maximum value of the larger error normalized to the length of executed path is less than 0.05 .

\section{7-DOF manipulator fixed through a force-torque measurement system to the base}

The second test facility is dedicated to testing the 7-DoF manipulator arm operating in three dimensional frame. The test bed contained three primary elements (Fig. 6): (i) a laboratory model of a 7-DOF manipulator, (ii) the base of the manipulator with a reaction force and torque measurement system and (iii) a constant-tension gravity-compensation system. The primary purpose of the second test bed was to gain experience in designing and developing manipulator components that would meet the requirements of space manipulators excluding the ability to operate in a vacuum. Another reason for this activity was a need for testing the algorithms that generate trajectories in a structure with many DoF's in a three-dimensional space. It is important to add that the manipulator arm is, by design, dedicated to operate in microgravity environ- 
ment, and therefore it is impossible to test it in terrestrial conditions without supporting system.

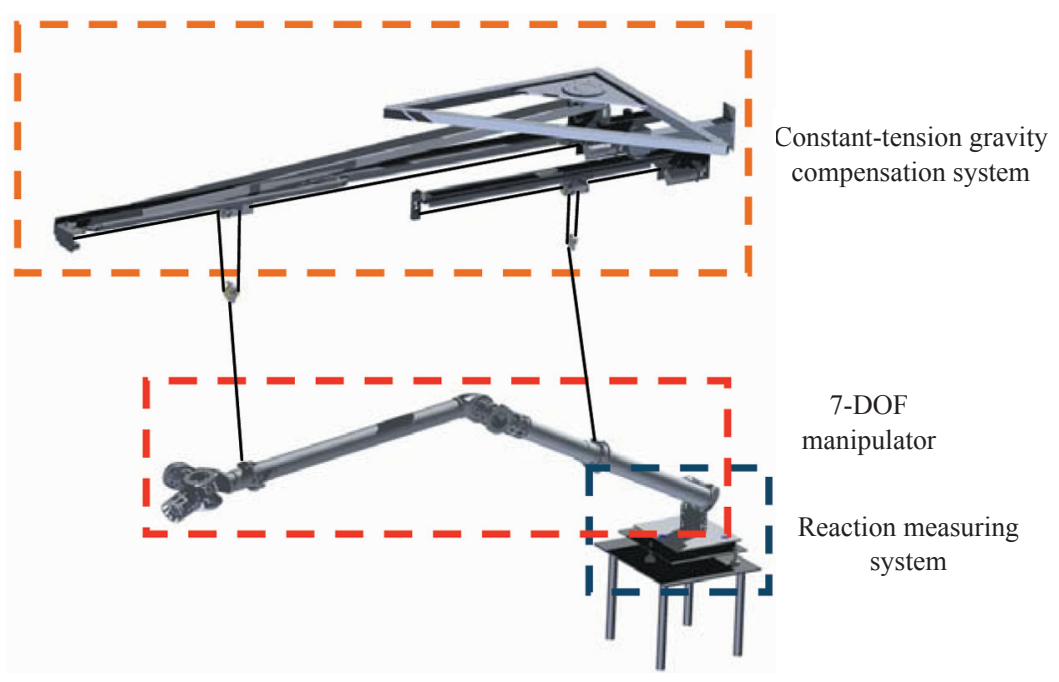

Fig. 6. 7-DOF manipulator test bed

\subsection{7-DOF manipulator}

Compared to the manipulator on the granite table, this manipulator has a fixed base and can operate in three-dimensional Cartesian space. The manipulator is a mechanical structure that consists of kinematic joints and links. The kinematic structure of the manipulator was selected based on simulations conducted for three typical manipulator manoeuvres: manipulator unfolding, realising a straight-line trajectory in a target reference frame and a target-service ridigisation phase. The details of the trade-offs of the selected system are provided in [23], and the chosen kinematic structure (either CAD model and final prototype) is provided in Fig. 7. The structure consists of 7 rotary joints and 2 major links. The manipulator's mechanical design was optimised for a minimum total mass. The primary mechanical performances are presented in Table 2.

Mechanical attributes of the 7-DOF manipulator

\begin{tabular}{|c|l|c|}
\hline & \multicolumn{1}{|c|}{ Parameter } & Value \\
\hline 1 & Mass & $23 \mathrm{~kg}$ \\
\hline 2 & Range & $3 \mathrm{~m}$ \\
\hline 3 & Number of DOFs & 7 \\
\hline 4 & Maximum torque in the joints & $20 \mathrm{Nm}$ \\
\hline 5 & Maximum angular velocity in the joints & $10 \mathrm{rpm}$ \\
\hline
\end{tabular}




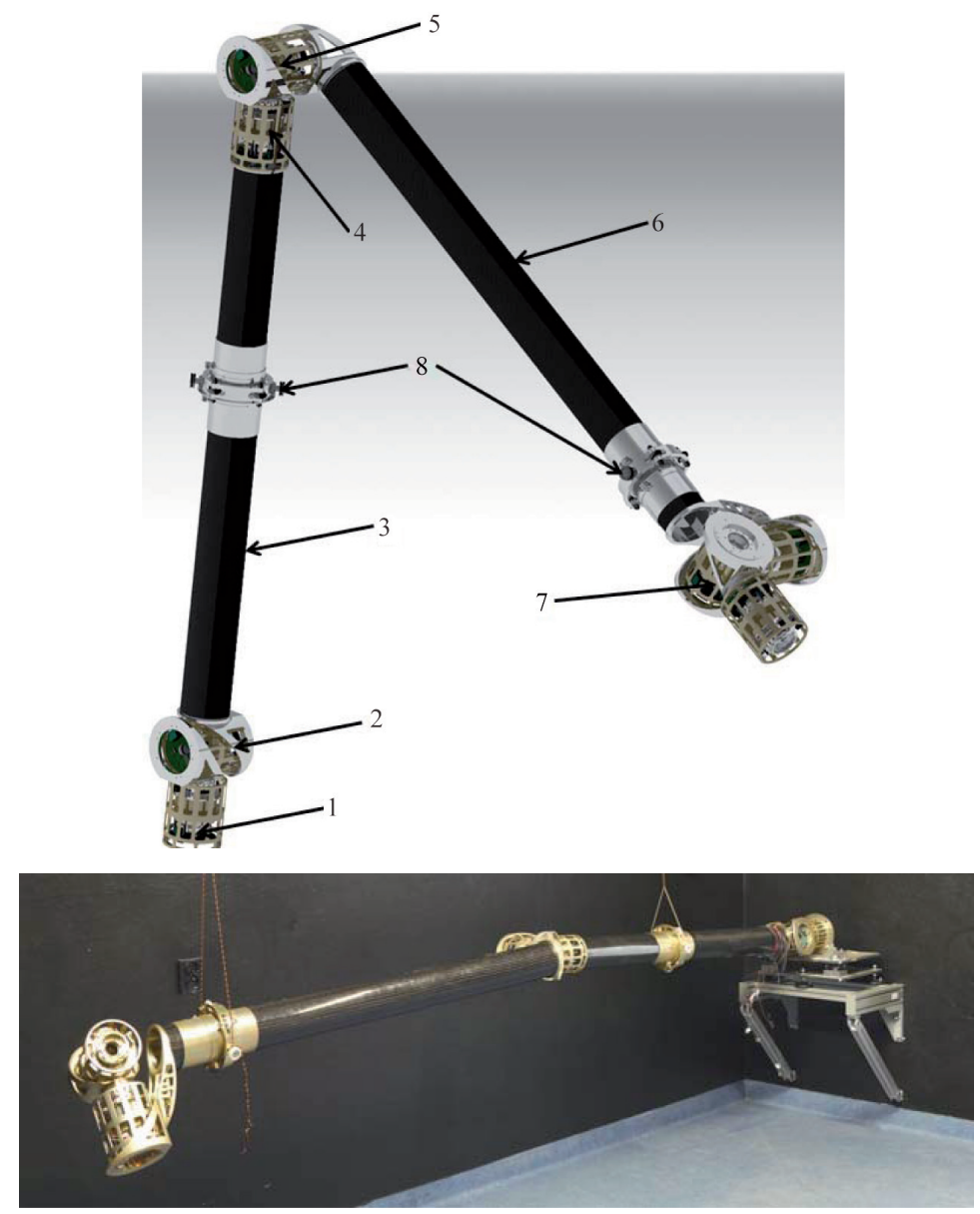

Fig. 7. 7-DOF manipulator: design on top view: 1 - first joint, 2 - second joint, 3 - first link, 4 - third joint, 5 - fourth joint, 6 - second link, 7 -3DoF end effector. The prototype on bottom view, 8 - attachments for gravity compensation system

During the development of the manipulator, special attention was focused on design of the joint. The final design consists of a cycloidal gear with optimally chosen parameters [24], a torque motor and control electronics. The application of a torque motor with high-efficiency gearing resulted in a high power density compared to the system's weight. The choice of this gearing type was dictated by many factors, including the requirement of a central hole through the gear to transfer electronic signals via slip rings and the need for a backlash-free transmission. However, the most important reason was the requirement of only rolling friction between the cooperating components, which in tribological terms is more advantageous in the context of mechanism adjustment when operating in a vacuum. An exploded view of the designed cycloidal gear is presented in Fig. 8. 


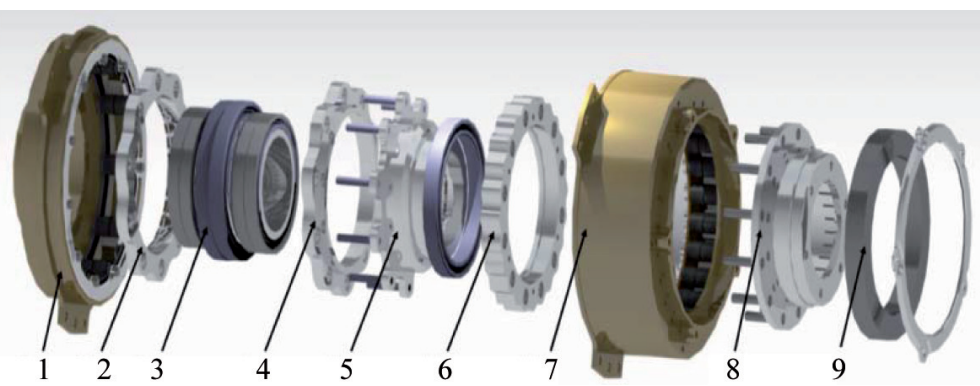

Fig. 8. Two-stage cycloidal gear design: 1 - ring with outer rollers, 2 - stage I cycloidal wheel, 3 - stage I eccentric shaft, 4 - stage I contra-rotating cycloidal wheel, 5 - stage I output shaft,

6- stage II cycloidal wheel, 7 - stage II ring with outer rollers, 8 - stage II output shaft, 9 - output crossed roller bearing

The gear described in Fig. 8 was placed in a kinematic pair, as shown in Fig. 9.

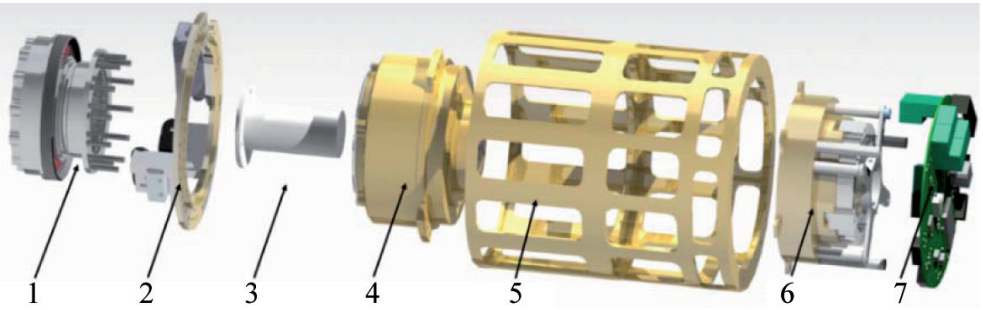

Fig. 9. 7-DOF manipulator kinematic pair design: 1 - kinematic pair output shaft with encoder, 2 - micro switch and encoder head unit, 3 - rotary electrical joint, 4 - two-stage cycloidal gear, 5 - housing, 6 - torque motor unit, 7 - joint control electronics

The primary problem in the development process of the cycloid gear was technological issues related to teeth accuracy and material composition. The latter issue was related to finding a balance between high tooth hardness and low mass.
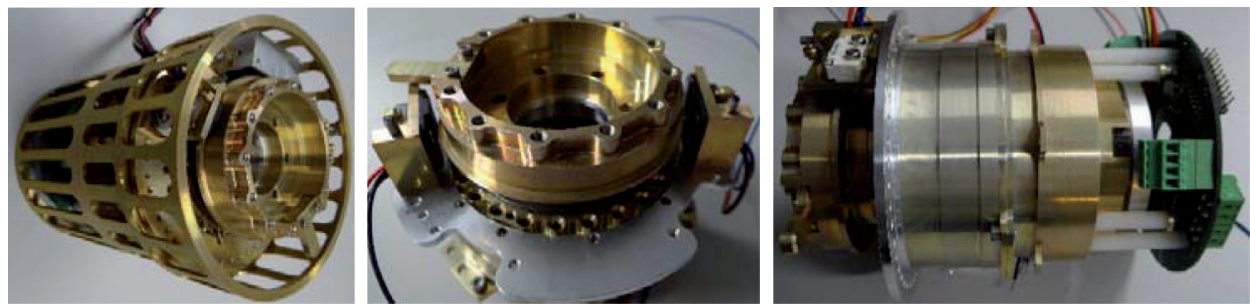

Fig. 10. Integrated first prototype of the kinematic pair: (from left) integrated kinematic pair in housing, unit of micro switches and encoder with an output shaft, integrated joint without housing with a torque motor 
During the development of the gear, dynamic simulations were performed to analyse the forces between the working teeth. First, the simplified rigid motion was analysed to determine, for example, the time range when the cycloidal disc experienced the highest load in an operating cycle. Later, the full transient analyses in Ansys software were conducted [24]. In the dynamic analysis, the shape of the cycloid disc was described as a curve cycloid created by the outer or inner rolling method. In this paper, only a cycloid curve with one tooth difference between the cycloid disc and sun ring is considered. The general equation describing the epicycloid curve in Cartesian coordinates is presented in Eqs. 1 and 2 [25]:

$$
\begin{aligned}
& x(\theta)=R_{z} \cos (\theta)+e \cos (N \theta)-q \cos \left(\theta+a \tan \left(\frac{\sin (z \theta)}{1 / \lambda+\cos (z \theta)}\right)\right) \\
& y(\theta)=R_{z} \sin (\theta)+e \sin (N \theta)-q \sin \left(\theta+a \tan \left(\frac{\sin (z \theta)}{1 / \lambda+\cos (z \theta)}\right)\right)
\end{aligned}
$$

where:

$R_{z}$ - radius of the arrangement of the rollers in the sun ring,

$q$ - coefficient of the shortened cycloid (radius of the rollers in the sun gear),

$\lambda$ - attitude tooth head to the base,

$i$ - gear ratio,

$\theta$ - angle of the cycloid in a curve.

$N$ - number of rollers in outer ring.

$z$ - number of tooth in cycloid wheel.

Considering the curve equation of the cycloid disc and the sun ring geometry (Fig. 11), 6 independent parameters of the cycloid gear (e.g., $R_{z}-$ radius of the arrangement of the rollers in the sun ring, $q$ - coefficient of the shortened cycloid (radius of the rollers in the sun gear, $r_{p}$ - radius of the arrangement holes and pins in the low speed mechanism, $\lambda$ - attitude tooth head to the base, and $d_{p}$ - diameter of the pins in low speed mechanism) are defined. Based on the results from the FEM simulations, the best option was chosen with the following parameters $\left(R_{z}=31 \mathrm{~mm}, q=6.5 \mathrm{~mm}\right.$, $\lambda=0.5$ ). Table 3 shows the dynamic forces between the teeth depending on the attitude from the tooth head to the base (i.e., $\lambda$ ). These simulations helped us to define the optimal parameters of the epicycloid gear in terms of efficiency and weight. 


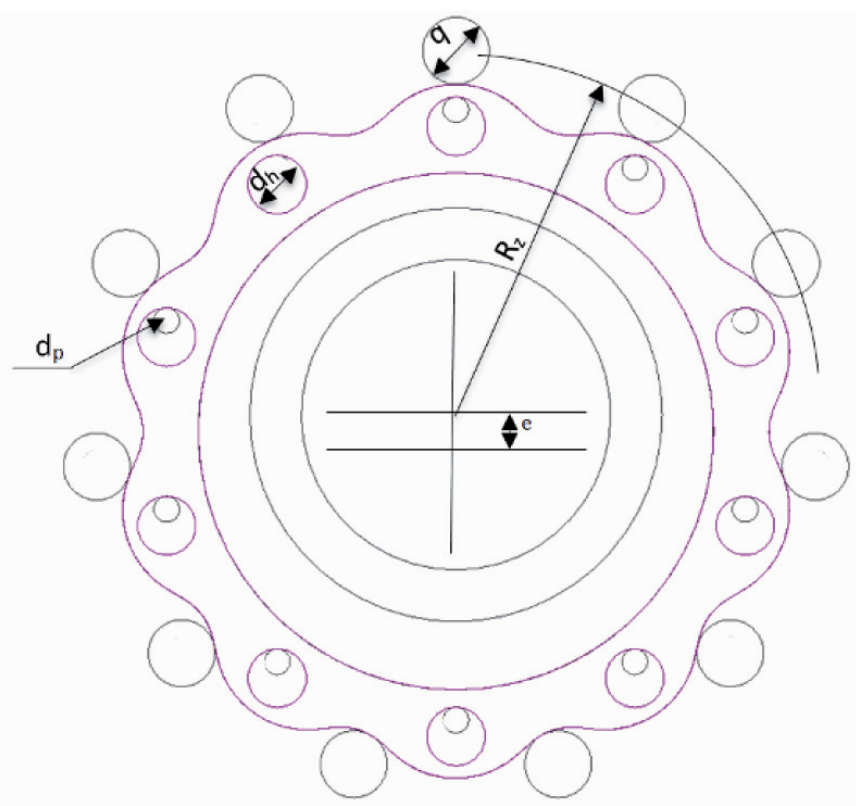

Fig. 11. Geometric parameters in the epicycloid one stage gear

Table 3.

Results from simulations on the variation of parameter $\lambda$

\begin{tabular}{|c|c|c|c|}
\hline$\lambda$ & $\begin{array}{c}E \\
(\mathrm{~mm})\end{array}$ & $\begin{array}{c}F_{\text {tooth } \max } \\
(\mathrm{N})\end{array}$ & $\begin{array}{c}\text { Weight } \\
(\mathrm{g})\end{array}$ \\
\hline 0.45 & 1.375 & 10 & 9 \\
\hline 0.5 & 1.6 & 14 & 12 \\
\hline 0.6 & 1.87 & 5.2 & 15 \\
\hline 0.7 & 2.23 & 8 & 20 \\
\hline 0.8 & 2.56 & 5.5 & 22 \\
\hline
\end{tabular}

\subsection{Reaction measuring system}

The 7-DOF manipulator is installed on the base equipped with a system of 3 triaxial force sensors that measure reaction forces and moments acting on the base during the realisation of the set trajectory. These reactions are critical to understanding and validating satellite motion.

The design of the fixed base is presented in Fig. 12a. The arrangement of the sensors in the base is shown in Fig. 12b. Three triaxial force sensors allow for the calculation of the reaction torque and force where the manipulator is fixed. 

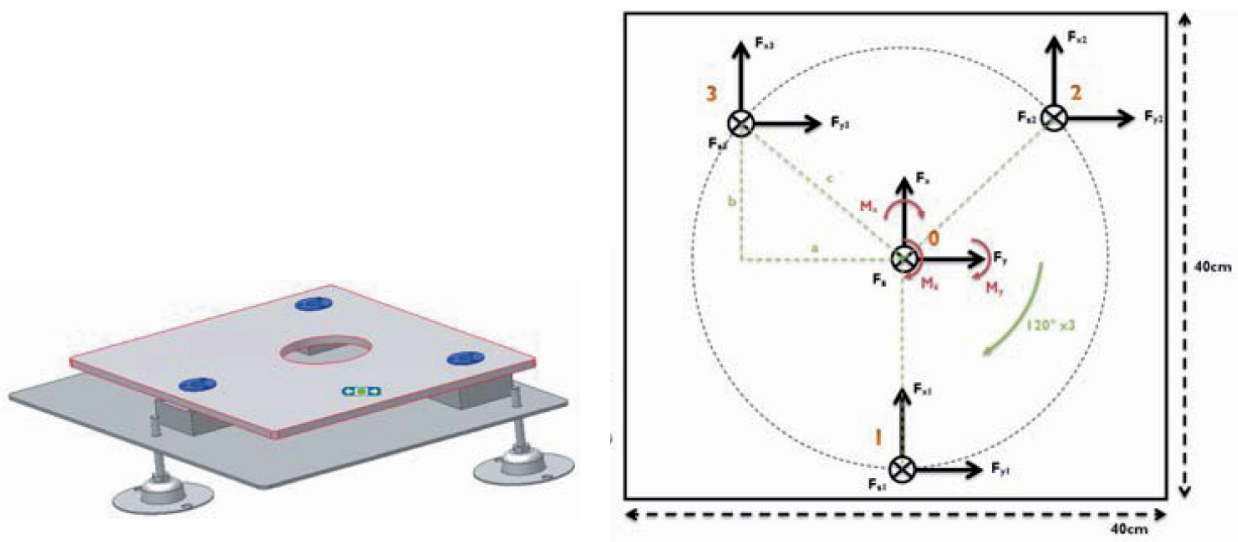

Fig. 12. Reaction measuring system. a) CAD model of the fixed base. b) Arrangement of the force sensors

Point " 0 " in Fig. 12b is where the 7-DOF manipulator is fixed, and points 1,2 and 3 are the locations of the force sensors.

\subsection{Constant-tension gravity compensation system}

A critical element of the three-dimensional test bed is the suspension system that emulates a zero-gravity environment on Earth's surface. By design, the required accuracy was to reduce the gravity effects by $95 \%$. This system consists of tracking lashings that generate a force directed opposite to gravity. These lashing attachment points were determined based on analyses and simulations. The designed system ensures that the generated forces act parallel to gravity in the established working area and under specific motion parameters. Because manipulator movement is performed around the base, a solution based on a system of two extension arms was selected, whose axes of rotation are near the manipulator base. The mechanical configuration of the microgravity emulation system is shown in Fig. 13. The system includes tracking subsystems with small and large extension arms, relief force generation subsystems of the small and large extension arms, and the controller and software to manage the system. In addition to the rotary and longitudinal motion of the short extension arm, all moving lashing components and the forces applied to the manipulator by the lashings are actively controlled.

For control purposes, we applied strain gauges and designed and implemented a vision system into the tracking subsystem of the large extension arm. The primary component of the gravity force is reduced by moment tape springs that have a constant moment of $1.87 \mathrm{Nm}$. These springs cooperate with Dunkermotoren GR63 x 25 DC motors $(50 \mathrm{~W}$, maximum instantaneous 
current of $27 \mathrm{~A}$ ) that correct the output force according to measurements of the sensors. The motor is able to correct up to $\pm 30 \%$ of the force generated by the spring, which enables the generation of relief forces within the range of $75 \pm 25 \mathrm{~N}$. The adjustment system was implemented in the controller using an Arduino platform. The controller settings can be changed using the associated software.

General information of the implemented system includes the following:

- Working area size (i.e., motion range of the lashing attachment points):

- small extension arm - area $1.7 \mathrm{~m}^{2}$, height $1.8 \mathrm{~m}$

- large extension arm - area $7.3 \mathrm{~m}^{2}$, height $2.05 \mathrm{~m}$

- Maximum lashing attachment point motion parameters:

- horizontal: velocity $2.5 \mathrm{~m} / \mathrm{s}$, acceleration $5 \mathrm{~m} / \mathrm{s}^{2}$

- vertical: velocity $1.3 \mathrm{~m} / \mathrm{s}$, acceleration $2.5 \mathrm{~m} / \mathrm{s}^{2}$

- Drive of the large extension arm, rotary motion - Dunkermotoren GR63x25 motor aided with a toothed gear

- Drive of the large extension arm, longitudinal motion - CrouzetDC42 (4.3 W, maximum instantaneous current $2.7 \mathrm{~A}$ ).

In Fig. 13, there is presented the photograph of the implemented station with the basic elements.

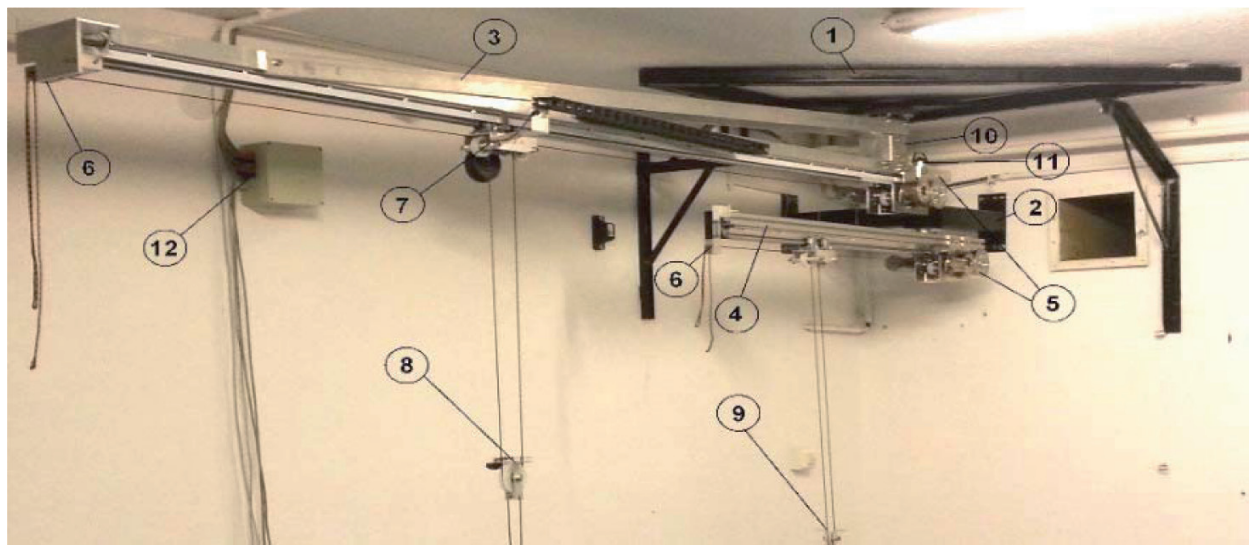

Fig. 13. Constant-tension gravity compensation system; 1 - big extension arm mounting,

2 - small extension arm mounting, 3 - big extension arm, 4 - small extension arm, 5 - spring and motor unit, 6 - strain force gauge, 7 - camera cart, 8 - lashing interface with marker, 9 - small extension arm lashing interface, 10 - big extension arm rotary motion drive, 11 - big extension arm longitudinal motion drive, 12 - controller

The expected measurement data from the testing system were calculated for the straight line trajectory realized by the manipulator arm end-effector during typical operation on satellites [26]. Due to safety reasons, in such ma- 
noeuvres the end effector follows the straight line trajectory defined in the target satellite reference frame, and the key issue is to know the reactions force generated on the satellite that disturbs the satellite's on-board attitude control system (AOCS). The system introduced in the paper allows for such measurements, assuming knowledge of the gravity contribution. In Fig. 14, the expected measurements are provided assuming 95\% reduction of the manipulator mass. After model correlation the expected impact on chaser satellite is provided in Fig. 15.

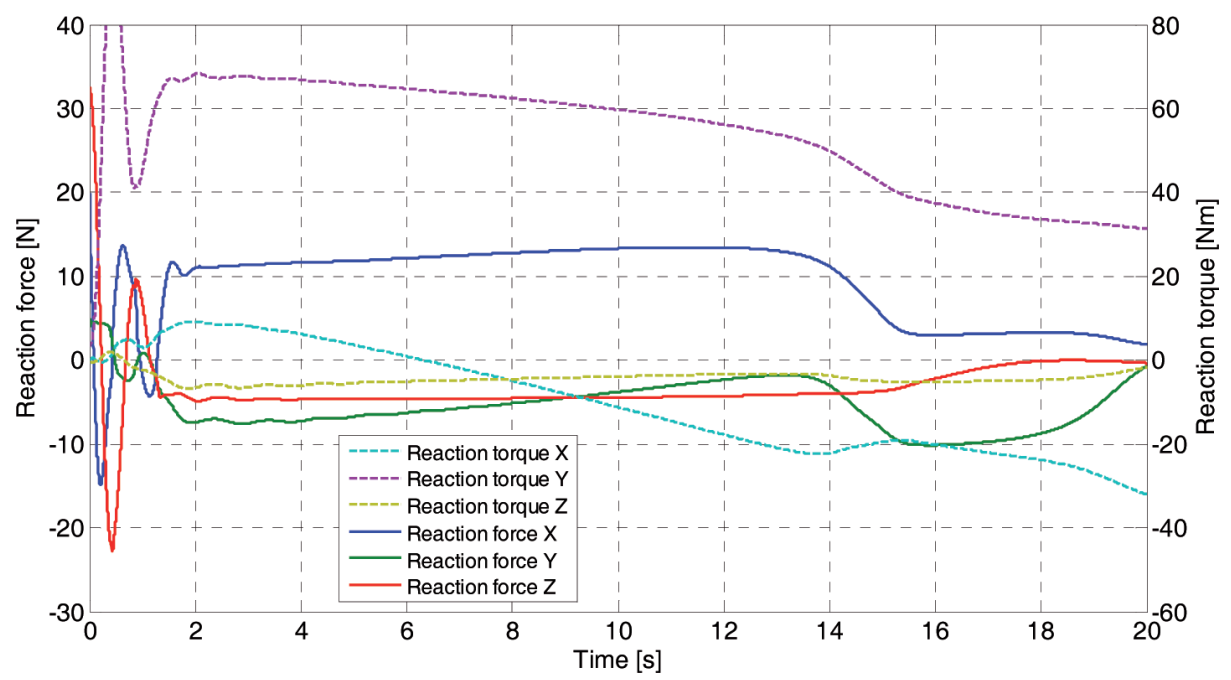

Fig. 14. The expected measurement of the force and torque with assumed $95 \%$ gravity reduction

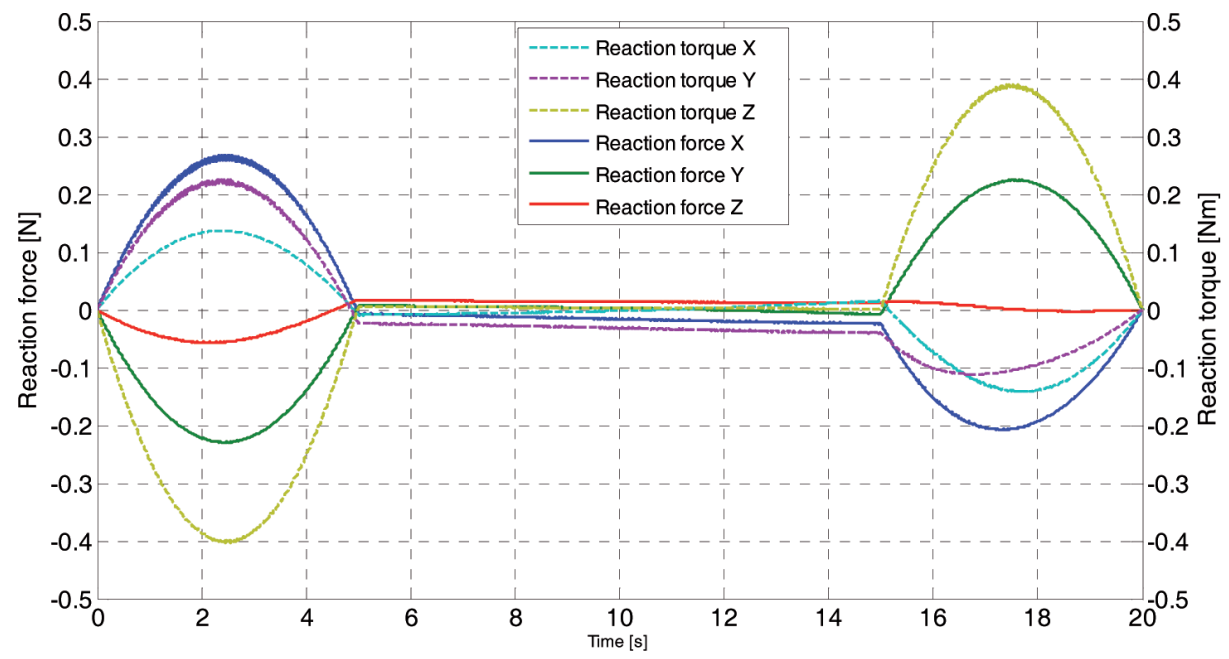

Fig. 15. The expected impact on chaser satellite. The data are provided for the manipulator mounting point on chaser satellite 


\section{Conclusions}

Within the framework of the project "Design and construction of a prototype of the manipulator as a key component of the satellite orbit servicing system", two test bed systems were presented in this paper. These test setups were developed parallel to the design of the WMS1 LEMUR space manipulator with aim to support the verification of the manipulator mechanical design as well as the operation of the manipulator control algorithm. The first prototypes were finished in 2014. The 2-DoF free floating system was fully successfully tested, while during initial assembling of the 7-DoF suspension system the problem with gravity reduction was detected. As an effect, it was difficult to reach smooth motion of the system.

In the future, the test beds will be enhanced with additional components to increase their capabilities. Future modification of the test bed on the granite table will include equipping the base of the system with cold gas thrusters and extending the control systems of the base's orientation and position. Future steps in the 7-DOF manipulator development process will include improvements of manipulator suspension system, and adding a gripper and small vision system operating as a relative end-effector position measurement system.

An air-bearing test bed system will also be used to test spacecraft landing gear dedicated to operating on bodies in near-zero gravity. The best example is Phobos, where the European Space Agency (ESA) plans its next mission, called the Phootprint.

\section{Acknowledgements}

The project "Design and construction of a prototype of the manipulator as a key component of the satellite orbit servicing system" was supported by the National Centre for Research and Development, under the LIDER/10/89/L-2/10/ NCBIR/2011 project.

Manuscript received by Editorial Board, February 20, 2015;

final version, July 30, 2015

\section{REFERENCES}

[1] T. Yasaka and W. Ashford, GSV: An Approach Toward Space System Servicing, Earth Space Review 5 (2), 9-17, 1996.

[2] Wenfu Xu, Bin Liang, Dai Gao, and Yangsheng Xu, A Space Robotic System Used for On-Orbit Servicing in the Geostationary Orbit. In proceedings of IEEE/RSJ International Conference on Intelligent Robots and Systems, Taipei, Taiwan, 2010.

[3] G. Visentin and D.L. Brown, Robotics for Geostationary Satellite Servicing, Robotics and Autonomous Systems 23, $45-51,1998$. 
[4] J. Kreisel, On-Orbit Servicing of Satellites (OOS): Its potential market \& impact, In proceedings of 7th ESA Workshop on Advanced Space Technologies for Robotics and Automation 'ASTRA 2002', ESTEC, Noordwijk, The Netherlands, 2002.

[5] K. Yoshida, Engineering Test Satellite VII Flight Experiments For Space Robot Dynamics and Control: Theories on Laboratory Test Beds Ten Years Ago, Now in Orbit, The International Journal of Robotics Research, vol. 22, no. 5, 2003.

[6] T.E. Rumford, Demonstration of autonomous rendezvous technology (DART) project summary, In: Proceedings of the Space Systems Technology and Operations Conference, Orlando, USA, 2003.

[7] A. Ogilvie, J. Allport, M. Hannah, J. Lymer, Autonomous satellite servicing using the Orbital Express Demonstration Manipulator System. In: Proceedings of the 9th International Symposium on Artificial Intelligence, Robotics and Automation in Space 'SAIRAS', Los Angeles, USA, 2008.

[8] Shin-Ichiro Nishida, Satomi Kawamoto, Yasushi Okawa, Fuyuto Terui, Shoji Kitamura, Space debris removal system using a small satellite. Acta Astronautica 65, 2009, s. 95-102.

[9] A. Flores-Abad, O. Ma, K. Pham, S. Ulrich, A review of space robotics technologies for on-orbit servicing, Prog. Aerosp. Sci. 68 1-26, 2014.

[10] R. Boumans, C. Heemskerk, The European robotic arm for the international space station. Robotics and Autonomous Systems, 23(1), 17-27, 1998.

[11] K. Krukewich, J. Sexton, K. Cavin, N.E. Lee, B. Cox, The systems engineering approach to the integration of the Space Station Remote Manipulator System on the International Space Station (ISS). Space Technology, 16(1), 31-48, 1996.

[12] A. Albu-Schäffer, Regelung von Robotern mit elastischen Gelenken am Beispiel der DLR-Leichtbauarme (Doctoral dissertation). Technische Universität München, 2002

[13] C. Menon, S. Busolo, A. Cocuzza, A. Aboudan, A. Bulgarelli, C. Bettanini, M. Marchesi and F. Angrilli, Issues and solutions for testing free-flying robots. Acta Astronautica 60 (12), 957-965, 2007.

[14] J. Schwarz, M. Peck and C. Hall, Historical Review of Air-Bearing Spacecraft Simulators, Journal of Guidance, Control and Dynamics 26 (4), 513 - 522, 2003.

[15] M. Marchesi, F. Angrilli and C. Bettanini, On Ground Experiments of Free-flyer Space Robot Simulator in Intervention Missions. In proceedings of 6th International Symposium on Artificial Intelligence, Robotics and Automation in Space 'i-SAIRAS 2001', St-Hubert, Quebec, Canada, 2001.

[16] M. Zebenay, Boge, T. Krenn, D. Choukroun, D., Analytical and experimental stability investigation of a hardware-in-the-loop satellite docking simulator, Acta Astronautica 00, 1-14, 2014.

[17] V. Barrena, Cost-effective Avionics Test Benches to support fast and iterative GNC Systems Design and Validation In proceedings of 7th ESA Workshop on Avionics, Data, Control and Software Systems - ADCSS, 2013.

[18] K. Seweryn, T. Rybus, J. Lisowski, T. Barciński, M. Ciesielska, K. Grassmann, J. Grygorczuk, M. Krzewski, T. Kuciński, J. Nicolau-Kukliński, R. Przybyła, K. Rutkowski, K., Skup, T. Szewczyk, R. Wawrzaszek, The laboratory model of the manipulator arm (WMS1 LEMUR) dedicated for on-orbit operation; In proceedings of I-SAIRAS conference, Montreal Canada, 2014.

[19] E. Papadopoulos, I.S. Paraskevas, T. Flessa, K. Nanos, G. Rekleitis and I. Kontolatis, The NTUA Space Robot Simulator: Design \& Results. In proceedings of 10th ESA Workshop on Advanced Space Technologies for Robotics and Automation 'ASTRA 2008', ESTEC, Noordwijk, The Netherlands, 2008.

[20] K. Seweryn and M. Banaszkiewicz, Optimization of the trajectory of an general free - flying manipulator during the rendezvous maneuver. In proceedings of AIAA Guidance, Navigation and Control Conference and Exhibit 2008, Honolulu, Hawaii, USA, 2008. 
[21] T. Rybus, T. Barciński, J. Lisowski, J. Nicolau-Kukliński, K. Seweryn, M. Ciesielska, K. Grassmann, J. Grygorczuk, M. Karczewski, M. Kowalski, M. Krzewski, T. Kuciński, R. Przybyła, K. Skup, T. Szewczyk, R. Wawrzaszek, New Planar Air-bearing Microgravity Simulator for Verification of Space Robotics Numerical Simulations and Control Algorithms, In proceedings of 12th Symposium on Advanced Space Technologies in Robotics and Automation, 2013.

[22] T. Rybus, K. Seweryn, Manipulator trajectories during orbital servicing mission: numerical simulations and experiments on microgravity simulator, In proceedings of EUCASS conference, Kraków, Poland, 2015.

[23] T. Rybus, J. Lisowski, K. Seweryn, T. Barciński, Numerical Simulations and Analytical Analysis of the Orbital Capture Maneouvre as a Part of the Manipulator-Equipped Servicing Satellite Design. In proceedings of 17th International Conference on Methods and Models in Automation and Control (MMAR'2012), Miedzyzdroje, 2012.

[24] K. Seweryn, K. Grassmann, M. Ciesielska, T. Rybus, M. Turek, Optimization of the Robotic Joint Equipped with Epicyloidal Gear and Direct Drive for Space Applications, In proceedings of 15th European Space Mechanisms and Tribology Symposium (ESMATS 2013), ESTEC, Noordwijk, Netherlands, 2013.

[25] Chen BingKui, Fang TinTin, Li ChaoJang, Wang ShuYan, Gear Geometry of cycloid gears, Science in China press, Springer, 2008.

[26] T. Rybus, K. Seweryn, M. Banaszkiewicz, M. Macioszek, B. Maediger, J. Sommer, Dynamic simulations of free-floating space robots, Lecture Notes in Control and Information Sciences, vol. 422, pp. 351-36, 2012.

\section{Projekt i budowa dwóch modeli laboratoryjnych manipulatorów jako kluczowy element stanowiska testowego dedykowanego robotom kosmicznym}

\section{Streszczenie}

Podczas procesu projektowania układów sterowania robotów pracujących w warunkach mikrograwitacji niezbędna jest możliwość przeprowadzenia ich walidacji w relewantnym środowisku. Kluczowym problemem jest budowa stanowisk testowych pozwalających na analizowanie ruchu manipulatora umieszczonego na swobodnej bazie, której ruch odbywa się w trzech wymiarach. Artykuł zawiera opis dwóch stanowisk testowych wykorzystywanych do analizy działania algorytmów sterowania w zrobotyzowanych systemach satelitarnych. W artykule opisano symulator warunków mikrograwitacji w postaci manipulatora płaskiego ze swobodną bazą umieszczoną na łożyskach powietrznych oraz stanowisko testowe wyposażone w manipulator o 7 stopniach swobody z utwierdzona bazą pozwalającą na pomiar 3 składowych siły i momentu siły. 